\title{
ARQUITECTURA Y RACIONALISNIO: ESPACIO MONOLÓGICO Y ESPACIO DIALÓGICO
}

\author{
Josep Muntanola Thornberg \\ (ETSAB Universitat Politécnica de Catalunya)
}

\section{Resumen}

La conmemoración del pensamiento de Descartes, es una buenil ocasión para reflexionar sobre el origen, tal vez por incomprensión, de algunas interpretaciones del espacio en la arquitectura contemporánea, en especial de aquellas que tienen como modelos a las planificaciones del siglo xix a gran escala, como el "Eixample" de Barcelona.

Mi comunicación analizará algunos textos de Descartes en los que se plantean por primera vez de forma explicita las relaciones entre los esquemas espaciales geométricamente homogéneos y el pensamiento de un solo hombre, otorgando a este tipo de pensamiento un nivel superior al que resulta del pensamiento de varios seres pensantes en el mismo lugar. Tanto este tipo de planteamientos como la base ética que los rodea tuvieron gran influencia en la defensa de un espacio homogéneo internacional como base necesaria para una modemización de nuestro espacio físico y social.

Mi reflexión acaba con una definición de arquitectura dialógica, en la que, de acuerdo con el pensador suizo J.B. Grize, no existe coincidencia universal entre trama espacial y pensimiento individual, más que en tanto en cuanto el espacio y el cerebro se digitalicen mutuamente a través de una arquitectura monológica, lo cual da su "razón" a Descartes.

\section{Capítulo I: Descartes y el planeamiento del espacio monológico moderno}

Descartes es un filósofo complejo y algo engañoso, que nunca deja claro si no nos dice lo que sabe porque tiene miedo a la iglesia, porque nos quiere hacer ver que sabe más de lo que sabe o porque es más poderoso de lo que dice ser y nos envuelve en su politica. De ahi que, al menos lasta E. Kant, la lógica y la ética del espacio siguieron muy confusos, y que el fantasma de un espacio monológico persiga todavia hoy a muchos de los defensores de la modernidad.

Descartes deja bien claro este punto crucial y polémico de su pensamiento en diversos momentos de su vida, y muy especialmente en su "discurso del método" en el podemos leer:

\begin{abstract}
Unos de mis primeros pensamientos fue el que me sugirió considerar que no hay tanta perfección en las obras compuestas por varias piezas y hechas por varios inaestros (de obras) que en las que un solo maestro a trabajado. Asi las obras en las que un solo arquitecto ha trabajado y acabado son mejores y mis ordenados que las que varios han intentado reacomodarlas haciendo servir viejas murallas para algo para lo que no estaban previstas.
\end{abstract}

En las ciudades antiguas... a partir de la manera en que están ordenadas, aquf algo grande, allá algo pequeito, y con las calles tortuosas y diferentes, más parece la fortuna que la razón de los hombres, la que las ha dirigido...

Nada que objetar, al contrario, sobre el aspecto lógico de un pensamiento individual que se desarrolla universalmente de lo más elemental a lo más coniplejo. Nuestro mundo digitalizado, en el que cada individuo intenta "navegar libremente" será una prueba siglos después. Muchos menos todavia, deberia objetarse el deseo de "refundar" constantemente la existencia 
propia sobre el pensamiento propio, evitando en lo posible los a-prioris de un legado histórico con un "pensamiento" distorsionado, anticuado.

Pienso, sin embargo, que en los textos citados asoma ya el problema, o el drama, que se esconde tras esta refundamentación lógica que, desde Descartes hasta hoy, no deja de preocuparnos, pasando a través de Kant, Hegel, Husserl, o, más recientemente de Paul Ricocur. Me refiero a las relaciones entre historia y pensamiento, que quedan bien patentes en las distintas concepciones de lo que es la intersubjetividad, y que, en el terreno de la arquitectura, se manifiestan bajo la alternativa entre monologia y dialogia socio-fisicas. tema clave de cualquier aproximación teórica contemporánea al espacio humano.

Paul Ricoeur ha sido, quizás, el filósofo que en los u̇ltimos arlos ha puesto más claramente de manifiesto la importancia de este punto preciso de la filosofia moderna, analizando las sutiles relaciones entre Descartes, Kant, Husserl y Hegel, para concluir, con Husserl y Gadamer sobre todo, que no hay "medición total entre historia y verdad", por lo que una explicación monológica de la historia es algo que hay que abandonar, e, indica Paul Ricoeur, abandonar no por que sea o no falsa, sino por que si se acepta obliga a pensar y a existir en una colectividad en la que cada individuo piensa y existe presuponiendo que los demás piensan y existen de la misma manera. Se nota pues que Ricoeur quiere controlar al diablo que anda suelto, al menos, desde Descartes.

Visto desde la arquitectura, y tal como lo plantea Descartes, el espacio nos ofrece un ejemplo excelente de este drama: De un lado, cada arquitecto construye "su" mundo, la suma de estos mundos, según Descartes, es imperfecta; de otro lado una ciudad hecha por un arquitecto único ha de ser superior por existir una singularidad histórica universal que asegura el puente entre lógica, ética y estética que el espacio humano debe construir. Todo ello dentro de una visión monológica de la intersubjetividad en la que todos han de participar de la misma red espacio temporal para construir un pensamiento singular universal. Como intentaré definir en la segunda parte de esta reflexión, desde el siglo xix hay muchas teorias y prácticas de la arçuitectura y del urbanismo que han aceptado estas premisas. Dicho de manera muy simple, diriamos que si por un lado la transparencia lógica es la mejor garantia de que no se manipula la sociedad con la planificación del espacio, por otro lado, esta misma transparencia produce una indiferencia hacia la historia, hacia cualquier diferencia fisico o social, hacia cualquier cambio exterior al "sistema de la transparencia", y encamina la sociedad al totalitarismo.

No es Descartes el primero en plantear la arquitectura y el espacio como ejemplo privilegiado de su filosofia. Aristóteles ya planteaba muclıo antes, que la "virtud-sabia" del arquilecto era la clave para entender sus libros de ética, $y$, con esta inteligente estrategia, resolvia de paso el problema de la forma regular o irregular del lugar construido. Simplemente lo regular o lo irregular correspondia a formas diferentes de "virtuosismo-sabio" para proveer formas de vida, "historias", diferentes, en lugares y situaciones temporales distintas, y con "constituciones politicas" propias. De este modo, las relaciones entre forma, del lugar, historia y pensamiento, tanto en lo lógico, lo ético o lo estético, se resolvian en un problema de relativa adecuación entre sociedad, historia y lugar, sin precisar si lo singular individual o lo singular colectivo eran o no incompatibles. Eran "figuras" urbanisticas que dialogaban entre lo local y lo universal.

En unos de sus últimos libros, F. Derrida, replantea este tema "de-construy'endo" el texto de Platón, TIMEO, con gran inteligencia. ${ }^{1}$ Por esta vez, la "de-construcción" "re-construye" un

I Derrida, F. KHORA. Galilet. Paris. 199.4. y Muntanola, J. La topogense: pour une architechure vivante. Anthropos. Paris. 1996. 
texto muy dificil de entender hoy. Sus conclusiones, a mi entender, se acercan mucho a la postura aristotélica de que lugar y historia no pueden nunca identificarse, y de que la relación entre un lugar y su contenido es extremadamente compleja, implicando necesariamente la política.

Descartes ve inmediatamente los problemas que plantea el diablo monológico que deja suelto al indicar que "éticamente" hay que ser fiel a la historia, al menos, "provisionalmente", lo cual no hace más que agravar el dilema anunciado, y abrir todavía más las puertas a un totalitarismo, que como los españoles sabemos bien, se apoya siempre en "éticas" y en "leyes" "provisionales" y "de excepción".

Volviendo, a la arquitectura, en un libro reciente he precisado la significación profunda de esta oposición entre monologia y dialogia a partir de diversas fuentes cientificas, algunas muy innovadoras. ${ }^{2}$ Siguiendo a Paul Ricoeur, quizás deberiamos pensar que "no podemos" apoyar a Descartes en su defensa por un pensamiento monológico, superior a los demás, singular universal, y, a la vez, delender la tolerancia y la paz. No "podemos" no solanente por ética y por estética, sino como indica valientemente este filósofo porque epistemológicamente no puede admitirse:

si un hombre o un grupo de hombres, o un partido político (o estado) se otorga el derecho del monopolio del saber hacer práctico, se otorgará también el derecho de definir el bien independientemente de lo que el bien es para los afectados.

Nunca la razón práctica puede pretender llegar a ser una fioría de la práxis, ya que, como advierte Aristóteles, "solamente existe saber de las cosas necesarias". La pretensión de unir un saber y una ética, que es el diablo que Descartes deja totalmente suelto, produce su mutua destrucción. Como veremos, algunos planificadores capitalistas del siglo xix vieron aquí un futuro esplendoroso y moderno. Por ello renunciar a Descartes, seria quizís el mejor homenaje que su genio se merece y la forma más racional de serle fieles, imitando su astucia.

\section{Capitulo II: Breves notas sobre Ildefons Cerdà y las manipulaciones entre verdad e historia en la Barcelona Moderna}

No resisto la tentación de describir muy brevemente un ejemplo excepcional que demuestra las virtudes y los vicios de este espacio "monológico" que Descartes dejó suelto bajo forma de diablo peligroso y ambiguo. Me reliero al "Eixample" de Barcelona de Ildefons Cerdil. El ejemplo es excepcional, no solo por su tamaño (más de 1000 manzanas con más de 2.000 habitantes potenciales cada una, algo asi como todos los pueblos de Catalunja juntos), sino por que en los últimos anos se ha convertido en unos de los fraudes históricos mejor construidos. Incluso se ha llegado a afirmar que bien se sigue ensanchando la trama Cerdà tal como es, o bien cualquier otra solución seria peor. El diablo conventido en "Fausto" condenado a crecer monológicamente, análogo a si mismo, por toda una cternidad...

Son demasindas las coincidencias entre Cerdà y el pensamiento "monológico" de Descartes, o de "un" Descartes, para ser casualidad. Tanto uno como el otro se dediearon a la "ingenieria". Descartes se negó a ejercer de ingeniero, aunque tuvo muchas ocasiones para cllo. en esto fue más listo que Cerda. Si Cerda no hubiese hecho el ensanche, hubiera pasado a la historia como el padre (teórico) del urbanismo moderno sin caer en las trampas práclicas del dia-

2 Op. cit, n-1 y tal "Ilermencutics, Semiotics and Archilecture". Semintica 1996. (Presentado en el Congreso Mundinl de Lingüistica, en Berke!ey, USA 1994). 
blo "monológico", tal como previó Descartes. Ambos defienden la superioridad de la regularidad geométrica sobre los "caprichos" de la historia antigua. Cerdà, en la práctica, desoye los consejos de Descartes del respeto "ético" por la historia a pesar de clefender la trama "lógica" universal para desmitificar: El ensanche arrasa todo lo que encuentra y si no le hubiesen "parado los pies", el diablo-trama se hubiese comido todo el parque de la "Ciutadella" y entrado a saco en la ciudad antigua, como, de hecho, lo está haciendo hoy, ya que, en parte la zona de derribos actual coincide con los planteamientos de Cerdà de atravesar con la trama toda Barcelona hasto el mar, caiga lo que caiga.

El tratamiento de los espacios públicos y de los espacios verdes es un modelo de contusión monológica. Cerdà no puede romper la pureza teórico-práctica de sus "alineaciones" diciendo que aqui habia un espacio verde o allá una iglesia. Se niega en redondo una y otra vez a ubicar espacios sociales; el libre intercambio ya lo resolverá y el ayuntamiento es un cliente como los demás. Total, no hay espacios sociales, todo se vende a manos privadas, incluso el nuevo solar público de las murallas (venta pactada antes de la aprobación del plan), y en los planos campea un color violeta en las manzanas (no verde) que legalmente es, para mi, la expresión más clara del diablo monológico: un espacio privado, legalmente, en el cual, en teoria, no hay nada de nada, pero que, en la práctica, se convierte en planta baja privada-comercial completamente separada del único espacio público, la calle, hecha para el trático rodado. EI peatón, ese ser molesto de los espacios monológicos, se queda sin espacios públicos exclusivos. ${ }^{3}$ Para colmo de confusión, y desoyendo todos los estudios sobre "L'Eixample" por parte de autoridades de prestigio mundial como Pierre lavedan a principios de siglo o Norman Everson hace pocos años, al ayuntamiento democrático de Barcelona se le ocurre convertir a Cerdà en símbolo de la democracia y del progresismo en el urbanismo mundial, y en víctima de la burguesia especuladora que impidió que Barcelona fuese la ciudad más "verde" del mundo y, a la vez, la más moderna. Se ha llegado a presentar a todas las escuelas de Barcelona un video "listórico - de hecho "ficción" - de cómo lubbiese sido el ensanche si se hubiese seguido a Cerdà; es decir con todos los centros de manzana públicos. Es uno de los ejemplos más diáfanos de la imposibilidad anunciada por Paul Ricoeur de mediatizar totalmente verdad e historia, y, por otra parte, uno de los fraudes históricos más sonados que demuestra, de paso, que historia y ficción siempre tienen que entrecruzarse. Lo que ocurre, es que, tal como el propio Ricoeur intenta demostrar una y otra vez siguiendo Aristóteles, la licción no presupone el fraude, sino, al revés, la garantia de libertad entre verdad y historia. La libertad se da, justamente, cuando se puede decidir entre ficción e historia, no cuando se "confunden" del todo o se separan del todo. Otros ejemplos de estas paradojas filosóticas esenciales son la retórica (nadie convence en un juicio si dice la verdad empirica a palo seco, hay que usar verosiniles tanto para condenar como para librar de una condena) y la poética: el mundo poćtico se separa del real solamente para verlo mucho más a fondo, no para crear una radical irrealidad, o un duplicado de la realidad, lo cual no tendría, en ningún caso, sentido "poético", etc, etc.

En este caso, por ejemplo, el fraude es tan claro, que en los debattes públicos sobre el interior "verde" $y$ la tesis de la tesis de espacios de Cerdà "verdes", se vuelve en contra de sus autores, y, como pasa en los actos forenses, estos "traspies" se pagan con la pérdida del juicio. El juicio se instala, pues entre verdad e historia. Allá lo coloca Kant y Ricoeur, y allá debe estar colocado.

3 Ver monografía de Magda Saura en al Escuela de Arquitectura de Bareeloma en 1982 con todos tos documentos originales transcritos: "El viller da la metodologia da l'Eixample". 
El espacio monológico, nuestro diablo que anda suelto, tiene además la virtud de confundir las cosas, de hacer imposible saber si algo será público, privado, verde o construido, y este ha sido siempre el paralso del especulador. También en el colmo del fraude se da la culpa del exceso de construcción a la burguesia! Burguesía a la que nunca gustó Cerdà. Desde Garriga i Roca hasta Puig i Cadafalch, pasando por cantidades de arquitectos y familias "burguesas" la ridicularización de Cerdà fue patente y es patente en las arquitecturas de edificios, parcelas etc. lo que, justamente, crea el encanto "extraio", y nada moderno de un ensanclie ecléctico opuesto ferozmente a lo monológico. Gaudi fue el que más duramente luchó en contra hasta lograr la avenida Gaudi para que pudiera verse la Sagrada Familia desde lejos, projectando una gran estrella asimétrica que, quizás, algún dia pueda construirse, pero seria a costa de romper la monología, de "dialogizarla", y ello, todavía hoy, chocaría con inuchos arquitectos "modernos" actuales que siguen creyendo que fue la trama homogenea la que nos trajo la prosperidad, la cultura y la fama. Luego, desde esta perspectiva se indica que algunos burgueses excéntricos quisieron impedir el progreso y el progresismo pero no lo consiguieron, triunfó la burguesía del progreso, de la modernidad, y asi se dejó al diablo suelto.

Podriamos seguir mucho más, hasta llegar a cientos de páginas sobre el ensanclie. Aquí solamente queria dejar claro las complejidades prácticas del juego monológico, complejidades a los que Descartes, ya viejo, se negó siempre. Prefirió ser pobre antes que perderse en lo que veía demasiado peligroso. Cerdà tuvo menos suerte, o mayor ambición, y murió totalmente marginado, victima de su propio diablo monológico. Probablemente nunca sabremos hasta que punto fue victima o verdugo.

\section{Capitulo IIl: Las salidas del Jaberinto:}

\section{Dialogías y monologías ел Ja arquitectura contemporánea}

Ya finalizando, debemos confirmar, que tras este ejemplo polémico, habrán muchos otros, como la cohesión entre intersubjetividad y espacio que tanto gustaba a Heidegger.

De hecho, no ha sido hasta hace poco que una explosión dialógica ha producido centenares de nuevos planteamientos en distintas perspectivas cientificas: Hawkins en astronomia. J. B. Grize y L. Apostel en la lógica matemática, la reciente heterocronología biológica o Jean Piaget en epistemología genética etc. En filosofia, el libro de F. Derrida L'Autre Cap, de dificilisima traducción, es un planteamiento dialógico. Por último, el éxito de M. Bakhtine ${ }^{4}$ con su antropologia "dialógica", no se comprendería sin esta situación favorable hacia una dialéctica entre una cultura "mundial" uniforme y una cultural "local" diferenciada. La identidad total, mundial, monológica, en al que el individuo "navega" pero no dialoga, y la identidad "local" que "dialoga" con otras identidades "locales", son dos mundos que se atraen y, a la vez, se repelen. En teoria no tendria por que existir dificultad en afirmar que el dialogo entre localidades espaciales y culturas "diferentes" se puede aumentar mediante las tramas, monológicas, liomogenizantes, siempre que éstas no anulen las diferencias, sino, al revés, las desarrolle. Se trata en suma, de convertir a los dos diablos, que son humanos, el monológico universal y el "local integrista", en ángeles en potencia, impulsando un cruce dialógico entre lo local y lo global, o como yo intento en mis escritos: desarrollando en cada lugar "local" aquella universalidad que solamente este lugar puede hacer posible, lo cual seria otra manera de expresar las opiniones

4 Todas las obras están coınentadas en la op, cit, nota I, y sobre Bakhtine es muy útil consultar el texio $y$ las notas del libro de S. Todorov: Le principe dialogique: $M$. Bakhine. Sobre la heterocronologia, ver M.L. Mickinney, Heterochron: the evolmtion of ontogen!. Plenum Press. 1991. 
de Bakhtine sobre la antropología cultural, o de Walter Benjamin sobre la esencia de la traducción. ${ }^{5}$ Benjamin asombró al decir que la posibilidad de traducción en todas las lenguas ya está en la lengua originaria que debe traducirse, y si no está ya en el texto originario no hay traducción posible.

Esta confianza en que la clave de lo universal (inter-lenguas) está en lo local, y que al destruir lo local: aquel pueblo medieval, aquella planta, aquel animal, se pierde posibilidad de univerdalidad, es la vía que, a la vez, paradójicamente, da y no da la razón a Descartes. Se la da porque otorga a lo individual un valor universal que no es intercambiable, no se la da, porque no acepta, (aunque nunca sabremos si Descartes, Hegel o Cerdà lo creyeron, lo hicieron ver o no se dicron ni cuenta) la existencia de una individualidad singular que media entre verdad e historia, estado y individuos, lógica y ética, economia y sociedad, o, finalmente espacio monológico y cultura. Lo individual solo es universal en cuanto es diferente, este "derecho a la diferencia" un de F. Derrida por una vez co-constructivo más que deconstructivo, y es sobre esta diferencia que se construye la trama monológica no destructiva. La teoria de Saussure fue un primer intento, pero hoy, en lingüistica, proliferan las dialógicas universales que simultanean, sin salirse de la lógica, el respeto a la diferencia a través de una proliferación de "figuras" y "conceptos" nuevos, para lo que hay que desarrollar una gran imaginación lógica, ética y estética. La imaginación - también aqui Ricoeur es importante- es la que lo consigue: "solo podemos ser expuestos a los efectos de la historia si podemos aumentar nuestra capacidad de ser afectados por ella. La imaginación es el secreto de esta competencia". Además, sin imaginación - ni ficción- yo no puedo dialogar con otro que es diferente, ni construir en un lugar y desde un lugar diferente. El arquitecto monológico construye siempre el mismo lugar en cualquier sitio, por lo que una trama homogénea es su lugar ideal, el que justifica la identidad entre sus edificios, puesto que la trama monológica es indiferente, a la vez, al lugar y a la historia; asi no necesita imaginación. Supongo que queda claro que no me refiero a la regularidad en sí de la trama como instrumento de planificación, sino a su uso, y' a la identificación entre una trama homogénea y un pensamiento superior que se supone -erróneamente- detrás de una trama irregular. Por lo tanto, hay que ensanchar sobre todo las "figuras" politicas, urbanisticas, de dialogo, ${ }^{6}$ que pongan en marcha una dialogia universal en la cual las nonologias tengan su papel, pero solamente su papel. La tolerancia tanto de lo universal como de lo local será condición necesaria para que estas "figuras" prosperen. Y pienso, por ejemplo, en la dificil "figura" espacio temporal del futuro de Yugoslavia.

¿Hay que encerrar estos diablos monológicos?. No lo creo, hay que dejarlos sueltos, porque son unos provocadores culturales y sociales profesionales excelentes que obligan a definir lo individual, lo local. Ya decía al principio que esto es para mi lo mejor de Descartes, su desafio a lo establecido, a la rutina, a la pereza mental de mediocridades establecidas. Pero "suelto" quiere decir "suelto", y no establecido. Por ello Descartes no quiso ejercer de ingenicro a pesar de la seguridad material aparente que ello conllevaba. $Y$ si hay algo "establecido", eso es el espacio monológico construido que arrasa lo natural, lo cultural y cualquier diferencia con la fuerza de una gigantesca apisonadora. Aqui, es preciso, hay que abandonar a quien sea: a

5 Op, cit nota 1.

6 Sobre las bases antropológicas de la dialogia, además de las indicadas, consultar la segunda edición de J. Muntanola La argutectura como lugar. Ediciones UPC. Barcelona 1996, con un indice temático informatizado. (Edición primera en 1974 también en Barcelona). También: Arquitectura espahola de los oilos ochenta. (Muntaiola, J.) Colegio de Arquitectos da Andalucia Oriental, 1990. 
Descartes, a Hegel, a Cerdà etc, si es que a estos individuos y a sus obras se les otorga la desgracia de defender tan estupidas actitudes y tan inútiles "figuras" urbanisticas, que son, además, totalmente "irracionales". Además, hay que dejar "suelto" también al diablo local, pero, ojo, tampoco aquí "establecido" en un caciquismo encerrado en sí mismo que prefiere la impermeabilidad al progreso, la pobreza al cambio. Cuando los dos diablos dialoguen entre ellos, algún ángel, como el de W. Wenders, relacionará el espacio y el tiempo para generar cultura. En este momento cualquier individuo será capaz de ver las diferencias entre tramas homogéneas distintas. Pero para ello habrán de dialogar muclıos diablos diferentes: iY no solamente a través de INTERNET! 